\title{
Use of Sonographic Contrast-enhanced Agents as an Alternative to Damaged Red Blood Cells for Imaging in Scintigraphy
}

\author{
Nordeval Cavalcante Araújo* \\ University of the State of Rio de Janeiro, Rio de Janeiro, Brazil
}

\begin{abstract}
Scintigraphy imaging is based on the uptake of radiopharmaceuticals by a tissue or organ. Hepatosplenic scintigraphy involves the uptake of labelled colloid by the mononuclear phagocyte system. The radiocolloid distribution in the body, where $80-90 \%$ is taken up by the liver, $5-10 \%$ by the spleen and $5 \%$ by the bone marrow, has the disadvantage of obscuring the rim of the spleen in patients with liver hypertrophy. However, the spleen takes up proportionally more particles if they are larger. While only $10-15 \%$ of $99 \mathrm{~m}$ Tc-sulfur colloid particles of $0.4 \mu$ diameter are taken up by the spleen, about $90 \%$ of denatured red blood cells (RBCs), approximately $7 \mu \mathrm{m}$ in diameter, are trapped in the splenic tissue. Because of this, labelled denatured RBCs are used for selective spleen imaging. RBCs present many disadvantages that preclude their use in clinical practice, as the steps involved in efficient labelling and denaturation of RBCs are labor-intensive, time-consuming, and not widely available. Therefore, an alternative method to denatured RBCs is highly desirable. Microbubbles, ultrasound-enhanced agents, are promising candidates for use as an alternative to damaged RBCs. Labelling of microbubbles is potentially simpler, safer, and less expensive. Furthermore, denatured RBCs and ultrasound contrast agents share certain characteristics, such as their size, shape, membrane composition and pharmacokinetics. Based on these similarities, the latter should be tested as an alternative carrier in scintillation scanning. Aside from the potential application of labelled microbubbles as a carrier alternative to denatured RBCs, they could also be used instead of natural RBCs for applications including the investigation of gastrointestinal bleeding, cardiovascular imaging studies, and to localize hemangiomas. Finally, they could be used in renal transplant recipients as a marker of rejection and as an adjunct to the diagnosis in certain diseases in which the immune response includes phagocytic cells.
\end{abstract}

\section{Introduction}

Scintigraphy is an imaging method which integrates the benefits of visualizing anatomical landmarks with functional findings, based on the uptake of radiopharmaceuticals by a tissue or organ. Once the organ or tissue has fixed the radiopharmaceutical, it emits gamma rays from the body which can be detected by a gamma camera, from which an image is created by means of a computer. ${ }^{1}$

Conventional hepatosplenic scintigraphy is performed following the injection of a labelled colloid that is phagocytosed by mononuclear phagocytic cells. Based on the size range of the

Keywords: Scintigraphy; Denatured red blood cells; Microbubbles; Liver; Spleen. Abbreviations: ${ }^{99 m} \mathrm{Tc}$, technetium-99m; RBCs, red blood cells; SPECT, single-photon emission tomography.

Received: March 13, 2019; Revised: May 25, 2019; Accepted: June 24, 2019

*Correspondence to: Nordeval Cavalcante Araújo, Hospital Universitário Pedro Ernesto - Nephrology Section, Boulevard 28 de Setembro, 77 - Vila Isabel, 20551030 - Rio de Janeiro, RJ, Brazil. Tel: 5521 2868-8127; E-mail: nordeval@oi.com.br How to cite this article: Araújo NC. Use of Sonographic Contrast-enhanced Agents as an Alternative to Damaged Red Blood Cells for Imaging in Scintigraphy. Exploratory Research and Hypothesis in Medicine 2019;4(3):65-68

doi: 10.14218/ERHM.2019.00006. radiocolloid particles, the distribution pattern usually mirrors the population of macrophages within the tissue, which is the case for liver, spleen and bone marrow scanning. ${ }^{2}$ During the performance of a scan with labelled colloid materials, the radiopharmaceutical localization follows a well-known organ distribution pattern in the body, with $80-90 \%$ being taken up by the liver, $5-10 \%$ by the spleen, and $5 \%$ by the bone marrow. ${ }^{3}$

The relatively higher liver uptake presents a disadvantage, in that it obscures the rim of the spleen in patients with hypertrophy of the left lobe of the liver. ${ }^{4}$ However, it is well established that the ratio of radiocolloid taken up by the liver, spleen and bone marrow is correlated with the size of the particle. Accordingly, the spleen takes up proportionally more particles if they are larger, and the opposite occurs in the bone marrow, where uptake is higher if particles are smaller. ${ }^{5}$ Only $10-15 \%$ of technetium- $99 \mathrm{~m}\left({ }^{99 \mathrm{~m} T c}\right)$ sulfur colloid particles of $0.4 \mu \mathrm{m}$ in diameter are taken up by the spleen, while about $90 \%$ of denatured red blood cells (RBCs), approximately $7 \mu \mathrm{m}$ in diameter, are trapped in the splenic tissue. ${ }^{6}$

As a result, labelled, denatured $\mathrm{RBCs}$ are used for selective spleen scanning. ${ }^{7,8}$ Selective studies have been advocated as further investigations for the following reasons: "equivocal splenic defect on sulfur colloid scan", "poor visualization of the spleen", "detection of residual tissue postsplenectomy", "suspected abnor- 
Table 1. Ultrasound contrast agents commercially available

\begin{tabular}{llll}
\hline Market name & Shell composition & Gas & Reference \\
\hline SonoVue $^{\circledR}$ & Phospholipid & Sulfur hexafluoride & Package insert \\
Definity $^{\circledR}$ & Phospholipid & Octafluoropropane & Package insert \\
Optison $^{\circledR}$ & Human serum albumin & Octafluoropropane & Package insert \\
Sonazoid $^{\circledR}$ & Phospholipid & Perflubutane & Package insert \\
\hline
\end{tabular}

SonoVue by Bracco Imaging S.p.A.; Definity by Bristol-Myers Squibb; Optison by GE Healthcare Systems; Sonazoid by GE Healthcare.

malities of number and position", 8 "evaluation of accessory spleen/ splenosis", 9-11 and "for assessment of spleen function". ${ }^{12}$ Spleen scintigraphy using ${ }^{99} \mathrm{~m}$ Tc-heat denatured RBCs was also useful to distinguish between neuroendocrine tumors and spleen tissue. ${ }^{13}$

Although the use of radiolabeled, denatured RBCs has been demonstrated to be a good method for visualizing the spleen, it presents many disadvantages that preclude its use in clinical practice. RBCs have to be drawn from the patient, labelled and denatured, and then the final preparation must be reinjected into the patient. ${ }^{14}$ The steps involved in achieving efficient labelling and denaturation of RBCs are labor intensive, time-consuming, and not widely available. The need for $6-8 \mathrm{~mL}$ of whole blood to perform the method is an additional problem, especially when dealing with infants..$^{15}$ Therefore, an alternative method to the use of denatured RBCs that could overcome the aforementioned disadvantages is highly desirable.

Solid lipid nanoparticle, as an alternative to replace radiopharmaceutical used for liver-spleen imaging today, has showed a preferential uptake by the lungs. ${ }^{16}$

Microbubbles, ultrasound-enhanced agents, are potential candidates for use as an alternative to damaged RBCs in the field of scintigraphy. Denatured RBCs and ultrasound contrast agents share some characteristics. First, the diameter of denatured RBCs is around $7 \mu \mathrm{m},{ }^{6}$ while the diameter of microbubbles range from 2 to $6 \mu \mathrm{m} .{ }^{17}$ The size of the particle is crucial for selective uptake by the spleen. Second, similar to the membrane of RBCs,${ }^{18}$ the shell of most ultrasound contrast agents is composed of phospholipids (Table 1), which made them well suited for radiolabeling in the same manner as RBCs. Third, microbubbles and denatured RBCs are quite similar to each other in shape, as they are both spherical. This spherical shape plays an important role in its recognition by the spleen as a particle to be phagocytosed. Finally, both share the ability to distribute almost exclusively within the intravascular compartment of the body. ${ }^{19,20}$

Contrast-enhanced ultrasound of the spleen is able to show focal lesions in inhomogeneous splenic parenchyma on conventional ultrasound, to characterize accessory spleen or splenosis. ${ }^{21}$

The use of microbubbles composed of polyvinyl alcohol (not used in clinical diagnostic ultrasound) as biovector to radionuclides has already been reported. Indeed, in a study of single-photon emission tomography (commonly known as SPECT), ${ }^{99 \mathrm{~m} T c-}$ labeled multimodal microbubbles were found to be able to attach to inflamed areas, ${ }^{22}$ whereas in a multimodal imaging study using SPECT, computed tomography and magnetic resonance, the usefulness of a ${ }^{99} \mathrm{~m} T c-l a b e l e d$ microbubble functionalized with diethylenetriaminepentaacetic acid, thiolated poly(methacrylic acid), chitosan, 1,4,7-triacyclononane-1,4,7-triacetic acid, 1,4,7-triacyclononane-1,4,7-triacetic acid-super paramagnetic iron oxide nanoparticles (SPION), or diethylenetriaminepentaacetic acid1,4,7-triacyclononane-1,4,7-triacetic acid-super paramagnetic iron oxide nanoparticles enabled fusion of functional and anatomical information. ${ }^{23}$

\section{Hypotheses}

Based on the similarities in size, shape, membrane composition and pharmacokinetics between RBCs and microbubbles, we hypothesized that the latter would represent a good alternative carrier for use in scintillation scanning.

\section{Labelling of microbubbles}

${ }^{99} \mathrm{~m} \mathrm{Tc}$, the radioisotope most frequently used in nuclear medicine and the same used to label RBCs, should be used for labelling microbubbles. After reconstitution of the lyophilized microbubbles with saline provided by the manufacturer, stannous chloride and ${ }^{99 \mathrm{~m}} \mathrm{Tc}$ should be added directly into the same vial. ${ }^{24}$

\section{Advantage of microbubbles as a radiolabelled agent}

Compared to RBCs, the procedure for labelling microbubbles is simpler. At least two steps are excluded, as it is not necessary to take blood from the patient or conduct maneuvers to denature the RBCs. It is worth highlighting that these steps carry significant risk of contamination to both the operator handling the blood and the patient who will receive it. With regard to cost reduction, the use of microbubbles also presents an important advantage. The steps taken to isolate and radiolabeled RBCs require a high degree of sophistication to maintain sterility, including specialized facility design and equipment, ${ }^{25}$ which increases the final cost of the procedure.

\section{Future directions}

Aside from the use of labelled microbubbles as a carrier alternative to denatured RBCs, it is also theoretically possible that they could be used instead of natural RBCs in the investigation of gastrointestinal bleeding, ${ }^{26}$ for cardiovascular imaging studies, ${ }^{27}$ and to localize hemangiomas. ${ }^{28}$

\section{Prospective and prediction}

Kidney uptake of ${ }^{99 m}$ Tc-colloid as a marker of both acute and chronic rejection in renal transplant patients, ${ }^{29-32}$ in contrast to an absence of uptake in normal functioning grafts,${ }^{33}$ has been reported previously; however, according to a review in PubMed, the most recent study on this subject was published in $2005 .{ }^{34}$ One limitation of such studies is that the liver takes up around $90 \%$ of the injected radiocolloid. Therefore, assuming that the distribution of 
small colloid particles in the liver and spleen remains unchanged in renal transplant recipients, this would restrict the amount of radiocolloid available to attach to the kidney. On the other hand, it is reasonable to speculate that by using larger carriers, like labelled microbubbles, more particles would bypass the liver and remain available in the circulation, where they can be taken up by the kidney graft.

It is possible to speculate further that the proposed method could also be applied to different diseases to increase the diagnostic accuracy concerning the immunopathological mechanisms involved, particularly for diseases in which cells engaged in phagocytosis are involved, such as rheumatoid arthritis and systemic lupus erythematosus. ${ }^{35,36}$

It is reasonable to assume that the use of microbubbles as a radiotracer carrier is not only simpler and more convenient than denatured labelled RBCs but could also be implemented at a lower cost. If our hypothesis can be tested and conclusively proven, I am confident that the proposed method would expand the usefulness of scintigraphy as a diagnostic method.

\section{Acknowledgments}

The author states there is no financial relationship to disclose.

\section{Conflict of interest}

The author has no conflict of interests related to this publication.

\section{Author contributions}

All aspects related to the manuscript (NCA).

\section{References}

[1] Siegel JA. The Practice of Nuclear Medicine. Guide for diagnostic nuclear medicine. Reston, Virginia, Society of Nuclear Medicine, Inc. 2001:3.

[2] Saba TM. Physiology and physiopathology of the reticuloendothelial system. Arch intern Med 1970;126:1031-1052. doi:10.1001/archin te.1970.00310120093014.

[3] Gottschalk A. Radioisotope scintiphotography with technetium-99m and the gamma scintillation camera. Amer J Roentgen 1966;97:860868. doi:10.2214/ajr.97.4.860.

[4] McIntyre PA. Diagnostic significance of the spleen scan. Sem Nucl Med 1972;2:278-287. doi:10.1016/S0001-2998(72)80060-6.

[5] Kalin B, Sellin P, Von Krusenstierna S, Schnell PO, Jacobsson H. Effect of size fractionation on the distribution of an albumin colloid in the reticuloendothelial system of the mouse. Int J Rad Appl Instrum B 1991;18:817-820. doi:10.1016/0883-2897(91)90024-F.

[6] Spencer RP. Role of radiolabeled erythrocytes in evaluation of splenic function. J Nucl Med 1980;21:489-491.

[7] Marsh GW, Lewis SM, Szur L. The use of ${ }^{51} \mathrm{Cr}$ - labeled heat-damaged red cells to study splenic function. I. Evaluation of the method. $\mathrm{Br}$ J Haematol 1966;12:161-166. doi:10.1111/j.1365-2141.1966. tb05620.x.

[8] Armas RR. Clinical studies with spleen-specific radiolabeled agents. Semin Nucl Med 1985;15:260-275. doi:10.1016/S00012998(85)80004-0.

[9] Massey MD, Stevens JS. Residual spleen found on denatured red blood cell scan following negative colloid scans. J Nucl Med 1991;32:2286-2287.
[10] Ekmekçi Ş, Diz-Küçükkaya R, Türkmen C, Adalet I. Selective spleen scintigraphy in the evaluation of accessory spleen/splenosis in splenectomized/nonsplenectomized patients and the contribution of SPECT imaging. Mol Imaging Radionucl Ther 2015;24:1-7. doi:10.4274/mirt.40085.

[11] Kim J, Hwang H, Lee JS, Park J, Kim EY, Park I. Splenosis mimicking recurrence of renal cell carcinoma after radical nephrectomy: a case report. Korean J Urol Oncol 2016;14:176-180. doi:10.22465/ kjuo.2016.14.3.176.

[12] de Porto APNA, Lammers AJJ, Bennink RJ, ten Berge IJM, Speelman P, Hoekstra JBL. Assessment of splenic function. J Clin Microbiol Infect Dis 2010;29:1465-1473. doi:10.1007/s10096-010-1049-1.

[13] Werner C, Winkens T, Freesmeyer M. Splenic scintigraphy for further differentiation of unclear (68) Ga-DOTATOC-PET/CT findings: Strengths and limitations. J Med Imaging Radiat Oncol 2016;60:365369. doi:10.1111/1754-9485.12464.

[14] Atkins HL, Goldman AG, Fairchild RG, Oster ZH, Som P, Richards $\mathrm{P}$, et al. Splenic sequestration of $99 \mathrm{mTc}$ labeled heat treated red blood cells. Radiology 1980;136:501-503. doi:10.1148/radiology.136.2.7403531.

[15] Ehrlich CP, Papanicolaou N, Treves S, Hurwitz RA, Richards P. Splenic scintigraphy using Tc-99m-labeled heat-denatured red blood cells in pediatric patients: concise communication. J Nucl Med 1982;23:209213.

[16] Eroglu H, Yenilmez A. An Investigation of the usability of solid lipid nanoparticles radiolabelled with tc-99m as imaging agents in liverspleen scintigraphy. J Biomed Nanotechnol 2016;12:1501-1509. doi:10.1166/jbn.2016.2286.

[17] Quaia E. Microbubble ultrasound contrast agents: an update. Eur Radiol 2007;17:1995-2008. doi:10.1007/s00330-007-0623-0.

[18] Mohandas N, Gallagher PG. Red cell membrane: past, present, and future. Blood 2008;112:3939-3948. doi:10.1182/ blood-2008-07-161166.

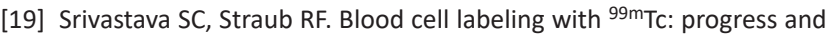
perspectives. Semin Nucl Med 1990;20:41-51. doi:10.1016/S00012998(05)80175-8.

[20] Greis C. Ultrasound contrast agents as markers of vascularity and microcirculation. Clin Hemorheol Microcirc 2009;43(1-2):1-9. doi:10.3233/CH-2009-1216.

[21] Omar A, Freeman S. Contrast-enhanced ultrasound of the spleen. Ultrasound 2016;24:41-49. doi:10.1177/1742271X15617214.

[22] Ahmed M, Gustafsson B, Aldi S, Dusart P, Egri G, Butler LM, et al. Molecular imaging of a new multimodal microbubble for adhesion molecule targeting. Cel Mol Bioeng 2019;12:15-42. doi:10.1007/ s12195-018-00562-z.

[23] Barrefelt ÅA, Brismar TB, Egri G, Aspelin P, Olsson A, Oddo L, et al. Multimodality imaging using SPECT/CT and MRI and ligand functionalized 99mTc-labeled magnetic microbubbles. EJNMMI Res 2013;3:12. doi:10.1186/2191-219X-3-12.

[24] Armas RR, Thakur ML, Gottschalk A. A simplified method of selective spleen scintigraphy with Tc-99m-labeled erythrocytes: clinical applications. Concise communication. J Nucl Med 1980;21:413-416.

[25] Zabel P, Robichaud N, Hiltz A. Facilities and equipment for aseptic and safe handling of blood products. J Nucl Med Technol 1992;20:236241.

[26] Emslie JT, Zarnegar K, Siegel ME, Beart RW Jr. Technetium-99mlabeled red blood cell scans in the investigation of gastrointestinal bleeding. Dis Colon Rectum 1996;39:750-754. doi:10.1007/ BF02054439.

[27] Wong GLM. Labelling of red blood cells with technetium-99m for nuclear medicine studies. Can J Hosp Pharm 1991;4:189-194.

[28] Royal HD, Israel O, Parker JA, Kolodny GM. Scintigraphy of hepatic hemangiomas: the value of Tc-99m-labeled red blood cells: concise communication. J Nucl Med 1981;22:684-687.

[29] Kim YC, Massari PU, Brown ML, Thrall JH, Chang B, Keyes JW Jr. Clinical significance of $99 \mathrm{~m}$ technetium sulfur colloid accumulation in renal transplant patients. Radiology 1977;124:745-748. doi:10.1148/124.3.745

[30] George EA, Meyerovitz M, Codd JE, Fletcher JW, Donati RM. Renal allograft accumulation of Tc-99m sulfur colloid: temporal quantitation and scintigraphic assessment. Radiology 1983;148:547-551. 
Explor Res Hypothesis Med

doi:10.1148/radiology.148.2.6346390.

[31] Massengill SF, Pena DR, Drane WE, Fennell RS, Richard GA. Technetium-99m sulfur colloid accumulation as a predictor of acute renal transplant rejection. Transplantation 1992;54:969-973. doi:10.1097/00007890-199212000-00005.

[32] Solaric-George EA, Fletcher JW, Newton WT, Henry RE, Donati RM. Renal accumulation of $99 \mathrm{mTc}$ sulfur colloid in transplant rejection. Radiology 1974;111:465-466. doi:10.1148/111.2.465.

[33] Frick MP, Loken MK, Goldberg ME, Simmons RL. Use of 99mTc-sulfur colloid in evaluation of renal transplant complications. J Nucl Med 1976;17:181-183.
Araújo NC. Sonographic contrast agents in scintigraphy

[34] Einollahi B, Bakhtiari P, Simforoosh N, Amirjalali R, Bassiri A, Nafar M, et al. Renal allograft accumulation of technetium-99m sulfur colloid as a predictor of graft rejection. Transplant Proc 2005;37:2973-2975. doi:10.1016/j.transproceed.2005.08.022.

[35] Paiva CN, Arras RH, Magalhães ES, Alves LS, Lessa LP, Silva MH, et al. Migration inhibitory factor (MIF) released by macrophages upon recognition of immune complexes is critical to inflammation in Arthus reaction. J Leukoc Biol 2009;85:855-861. doi:10.1189/jlb.0108009.

[36] Wu Z, Zhang S, Zhao L, Fei Y, Wang L, Li J, et al. Upregulation of CD16monocyte subsets in systemic lupus erythematous patients. Clin Rheumatol 2017;36:2281-2287. doi:10.1007/s10067-017-3787-2. 